\title{
METHODS
}

\section{Guide wire distance marks for oesophageal dilatation}

University Hospital of South Manchester, Didsbury, Manchester D G Maxton

Correspondence to: Dr D G Maxton, University Hospital of South Manchester, Nell Lane, West Didsbury, Manchester M20 8LR.

Accepted for publication 24 July 1989
Figure 1: Diagram of guide wire marks relative to oesophageal (KAD) dilator.

\author{
D G Maxton
}

damaging it. Possibly more dangerously, if the operator fails to realise that the dilator has reached the end of the wire, the guide wire and dilator may be advanced together rather than the dilator on the guide wire. The simple addition of chemically etched distance marks on standard guide wires is described which may help prevent these problems.

Oesophageal dilatation equipment is designed for use under radiological screening but in practice many procedures are performed without if the stricture can be passed with the endoscope or the guide wire enters the stomach without hindrance. Problems may arise using nonscreening techniques if the initial length of guide wire in the stomach is not accurately known or during progressive dilatation if the guide wire is unwittingly withdrawn while the dilators are being changed. This can lead to the dilator impacting onto the flexible guide wire tip and

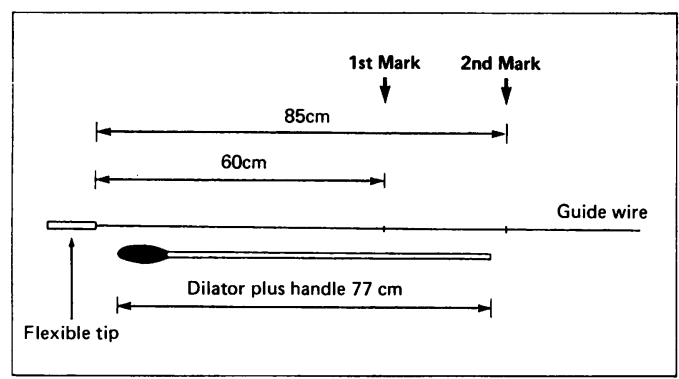

\section{Methods}

MATERIALS

A standard metal guide wire (Key Med, Southend-on-Sea, Essex) was chemically etched at two distances, a single mark $60 \mathrm{~cm}$ from the start of the flexible tip and a more distant double mark at $85 \mathrm{~cm}$ (Figs 1, 2). Such marks do not damage the wire or rub off with use. The distal double mark has a dual purpose. It is usually located near the mouth after the wire has been inserted and therefore its movement relative to the mouth easily and quickly shows if the guide wire is being retracted when dilators are changed over. In addition, as both Key-Med Advanced (KAD) and Eder-Puestow dilators measure approximately $75-80 \mathrm{~cm}$, when the double mark becomes visible as the dilator is inserted there remains only $5-10 \mathrm{~cm}$ before the dilator reaches the end of the wire. If the proximal $(60 \mathrm{~cm})$ single mark becomes visible at the teeth only about 20 $\mathrm{cm}$ of wire remain in the stomach and special care should be exercised.

\section{Discussion}

Distance marking of standard guide wires makes oesophageal dilatation safer and easier for the moderately experienced operator particularly if radiological screening is not used. Guide wire retraction and impending impaction of the dilator onto the flexible tip can then be identified at a glance. 